sión, que demostraron los beneficios en todos los subgrupos de la población estudiada, lo que indica que los beneficios de la vacunación se extienden incluso a un sector mucho más amplio de adultos mayores. El hecho de que las muestras analizadas procedieran de organizaciones de tres diferentes zonas geográficas aumenta la posibilidad de que estos resultados representen a poblaciones de otras partes de los Estados Unidos. Sin embargo, los adultos mayores atendidos en las HMO pueden diferir de los que no se atienden en estas organizaciones, tanto por sus características socioeconómicas y étnicas como por su lugar de residencia, y la generalización de estos resultados se debe hacer con cautela.

La reducción del riesgo de hospitalización por neumonía o gripe y de muerte en los adultos mayores que viven en la comunidad se mantuvo incluso durante las dos temporadas en las que no hubo una buena correspondencia entre la cepa circulante y la cepa empleada en la preparación de la vacuna. Por ello los pacientes, los proveedores de servicios de salud y los encargados de elaborar las políticas sanitarias deben renovar sus esfuerzos para mejorar la cobertura de vacunación contra la gripe en los grupos de mayor riesgo. (Nichol KL, Nordin JD, Nelson DB, Mullooly JP, Hak E. Effectiveness of influenza vaccine in the community-dwelling elderly. N Eng J Med. 2007;357(14):1373-81.)

\section{Factores de riesgo de la infestación de viviendas con triatominos en Colombia}

La enfermedad de Chagas o tripanosomiasis, causada por el parásito Trypanosoma cruzi, es la enfermedad transmitida por insectos de mayor incidencia en América Latina.

Algunos estudios han demostrado la relación existente entre las características de la vivienda y el nivel de infestación con triatominos - tanto dentro como en los alrededores del domicilio- y la prevalencia de la enfermedad. En este trabajo se presentan los resultados de un estudio transversal sobre la relación entre la presencia de anticuerpos contra T. cruzi en niños, el nivel de infestación y la calidad de las viviendas, a partir de una muestra inusualmente grande distribuida en una extensa área de Colombia. Este estudio se llevó a cabo entre 1998 y 2001 con métodos estandarizados y es el primero que se realiza con estas características en el norte de América del Sur.

Se evaluaron 41971 viviendas ubicadas en 3375 poblaciones. Estas poblaciones estaban localizadas en 539 municipios de 15 de los 32 departamentos de Colombia. Para probar la asociación entre dos medidas de infestación (haber visto tria- tominos en la vivienda y el envío de ejemplares al equipo de investigación) y 15 factores de riesgo de las viviendas se empleó la regresión logística multifactorial. El riesgo se determinó en relación con viviendas de referencia de $50 \mathrm{~m}^{2}$, con paredes de adobe sin emplastar, techos de paja y sin cobertizos ni animales domésticos, en las que vivían tres personas o menos.

De las 36873 viviendas de donde respondieron a la pregunta sobre si habían visto triatominos en el interior o en los alrededores, $8576(23,3 \%)$ respondieron afirmativamente. La probabilidad de ver triatominos fue mayor en las viviendas con más de siete habitantes (razón de posibilidades [odds ratio, $\mathrm{OR}]=1,24$; intervalo de confianza de 95\% [IC95\%]: 1,11 a 1,39), espacios de almacenamiento elevados (OR = 1,16; IC95\%: 1,03 a 1,32), cobertizo para granos (OR = 1,25; IC95\%: 1,02 a 1,52), gatos $(\mathrm{OR}=1,27$; IC95\%: 1,14 a 1,42$)$ y cerdos $(\mathrm{OR}=$ 1,16; IC95\%: 1,03 a 1,30). El menor riesgo se observó en las casas con paredes de madera $(\mathrm{OR}=0,46$; IC95\%: 0,34 a 0,61 ), paredes totalmente emplastadas (OR $=0,78$; IC95\%: 0,68 a 0,88), techos de tejas $(\mathrm{OR}=0,51$; IC95\%: 0,33 a 0,78$)$ y pisos de losas $(\mathrm{OR}=0,57$; IC95\%: 0,42 a 0,76).

Las especies enviadas con mayor frecuencia a los investigadores fueron: Rhodnius prolixus, de 554 viviendas (1,32\%); Panstrongylus geniculatus, de $220(0,52 \%)$; Triatoma dimidiata, de $205(0,49 \%)$; T. maculata, de $188(0,45 \%) ; R$. pallescens, de 93 $(0,22 \%)$; y $T$. venosa, de $70(0,17 \%)$. Se recibieron ejemplares de otras 13 especies de un total de 74 $(0,19 \%)$ viviendas.

Los factores de riesgo identificados - en correspondencia total con la información disponible acerca de la ecología de los triatominos-fueron: la presencia de animales domésticos y no domésticos (como roedores, ardillas y zarigüeyas), la existencia de almacenes con productos agrícolas y de construcción, y las características constructivas y las condiciones sanitarias deficientes de la vivienda.

Este estudió demostró que un mayor número de personas en la vivienda y la presencia de gatos y cerdos aumentó significativamente el riesgo de infestación. Las construcciones accesorias, como graneros y cobertizos elevados, ofrecen mayores posibilidades de vida y reproducción a los vectores, sin embargo, los mayores valores de OR correspondieron a las condiciones estructurales deficientes de la vivienda. Las viviendas con paredes, pisos y techos construidos con materiales de construcción más sólidos y compactos presentaron un menor riesgo de infestación.

El análisis de los resultados de este estudio hace notar la robustez estadística de la asociación encontrada entre las características de la vivienda y la probabilidad de infestación doméstica con triato- 
minos. Además, demuestra que la participación comunitaria puedes ser de gran ayuda para mapear y caracterizar la diseminación de los triatominos en extensas zonas y para identificar los factores de riesgo en las viviendas y sus alrededores. Estos resultados son de particular interés no solo para Colombia, sino también para otros países vecinos donde habitan los mismos vectores y las viviendas tienen características similares. (Campbell-Lendrum DH, Angulo VM, Esteban L, Tarazona Z, Parra GJ, Restrepo $\mathrm{M}$, et al. House-level risk factors for triatomine infestation in Colombia. Intl J Epidemiol. 2007; 36(4):866-72.)

\section{La gripe en Estados Unidos de 2006 a 2007 y la vacuna para 2007 a 2008}

En el período del 1 octubre de 2006 al 19 de mayo de 2007, la OMS y sus laboratorios colaboradores en los Estados Unidos (Sistema Nacional de Vigilancia de Virus Respiratorios y Entéricos) examinaron 179268 especímenes de virus y 23753 $(13,2 \%)$ dieron resultados positivos de gripe. De estos, $18817(79,2 \%)$ correspondieron al serotipo A y $4936(20,8 \%)$, al B. La proporción de positivos sobrepasó el 10\% la semana que terminó el 23 de diciembre de 2006, llegó al máximo de $28,6 \%$ en la semana que terminó el 10 de febrero de 2007 y bajó a menos de $10 \%$ en la semana que terminó el 28 de abril de 2007. Durante las tres temporadas anteriores, el porcentaje de especímenes positivos osciló de $22,6 \%$ a 34,7\% y el valor máximo se manifestó desde principios de diciembre hasta marzo. Durante 13 a 17 semanas consecutivas hubo más de $10 \%$ de resultados positivos, pero el porcentaje de defunciones por gripe y neumonía permaneció por debajo de los valores iniciales. Los virus A (H1) predominaron en esa temporada, si bien los A (H3) se aislaron con mayor frecuencia desde principios de marzo y predominaron en muchos países europeos y asiáticos.

En los Estados Unidos, los epidemiólogos informan de la distribución de la gripe en su propio estado o territorio mediante un código de actividad semanal de la enfermedad. Su mayor difusión se notó en la octava semana de 2007, cuando se extendió a 25 estados y 19 notificaron actividad regional. En 41 estados hubo actividad gripal dispersa por lo menos en una ocasión durante la temporada, pero en las semanas 16 a 20 de 2007 (en abril y mayo) la actividad de la gripe disminuyó. Durante las tres temporadas anteriores, el mayor número de estados informantes había variado de 41 a 50 . La mayor parte de los virus A (H1) se caracterizaron como A/Nueva Caledonia/20/99, que fue el componente de A (H1N1) recomendado para la vacuna de 200607. La mitad de los virus B del linaje B/Victoria se caracterizaron como B/Ohio/01/2005, el cual antigénicamente equivale al B/Malasia/2506/2004, componente $\mathrm{B}$ recomendado para la misma vacuna.

En los primeros meses de la temporada 200607, la mayor parte de los aislados A (H3) eran próximos a la cepa A/Wisconsin/67/2005, la A (H3N2) recomendada para inclusión en la vacuna. A fines de febrero de 2007, la mayor parte de aislados A (H3) mostraban títulos reducidos con antisueros producidos contra la cepa A/Wisconsin/67/2005.

En mayo de 2007, los Centros para el Control y la Prevención de Enfermedades (CDC) difundieron el aviso de la Red de Alerta de Salud de que había aumentado el número de defunciones pediátricas asociadas con gripe y coinfección por Staphylococcus aureus. En 2004-05 hubo solo una defunción pediátrica por esa causa, pero en 2005-06 se supo de tres defunciones. Durante el período del 1 de octubre de 2006 al 19 de mayo de 2007 ocurrieron 68 muertes infantiles asociadas con infecciones gripales, de las cuales 21 eran coinfecciones de gripe con S. aureus, tanto resistente como sensible a la meticilina.

En junio de 2007, en la reunión anual del Consejo de Epidemiólogos Estatales y Territoriales (CSTE), se ratificó la obligatoriedad de notificar al Sistema Nacional de Vigilancia de las Enfermedades las infecciones humanas por virus A novedosos. Estos se definieron como virus aislados de personas pero subtipificados como no humanos o virus que no pueden subtipificarse con los métodos estándar. Virus novedosos transmisibles de persona a persona podrían significar el principio de una pandemia y su pronta detección y caracterización aceleraría la ejecución de medidas protectoras de salud pública. También se mantuvo obligatoria la notificación al Sistema de Vigilancia de muertes pediátricas relacionadas con la gripe. Asimismo, los CDC siguen recomendando una vigilancia intensificada para detectar cualquier caso posible de gripe aviar A (H5N1) en viajeros con trastornos respiratorios importantes de causa desconocida, que hayan regresado al país hace poco tiempo tras visitar países afectados.

Sobre la base de análisis antigénicos de los virus de gripe aislados recientemente, datos epidemiológicos, estudios serológicos posvacunales y la disponibilidad de cepas de vacuna y reactivos, la vacuna trivalente contra la gripe recomendada para 2007-08 contiene cepas análogas a la A/Islas Salomón/3/2006 (H1N1), la A/Wisconsin/67/ 2005 (H3N2) y la B/Malasia/2506/2004. El único cambio en esta vacuna es el componente del virus A (H1N1). La cepa A/Islas Salomón/3/2006 es una variante antigénica reciente de la $\mathrm{A} / \mathrm{Nueva}$ Caledonia/20/99 usada en la vacuna 2006-07. (Centers for Disease Control and Prevention. Morb Mortal Wkly Rep. 2007;56(31):789-94.) 